\title{
The Usage of Automated External Defibrillator for Out-of-Hospital Cardiac Arrest Patients in Taichung city, Taiwan
}

ChihYu Chen, TaiLin Huang, HongMo Shih, WeiKung Chen

Emergency Department, China Medical University Hospital, Taichung, Taiwan

\section{BACKGROUND}

Early defibrillation is very important for ventricular defibrillation or ventricular tachycardia related out-ofhospital cardiac arrest patients. Automated external defibrillator was set in public area to decreasing the time to defibrillation in Taiwan since 2013. However the usage and effect of automated external defibrillator remained unknown.

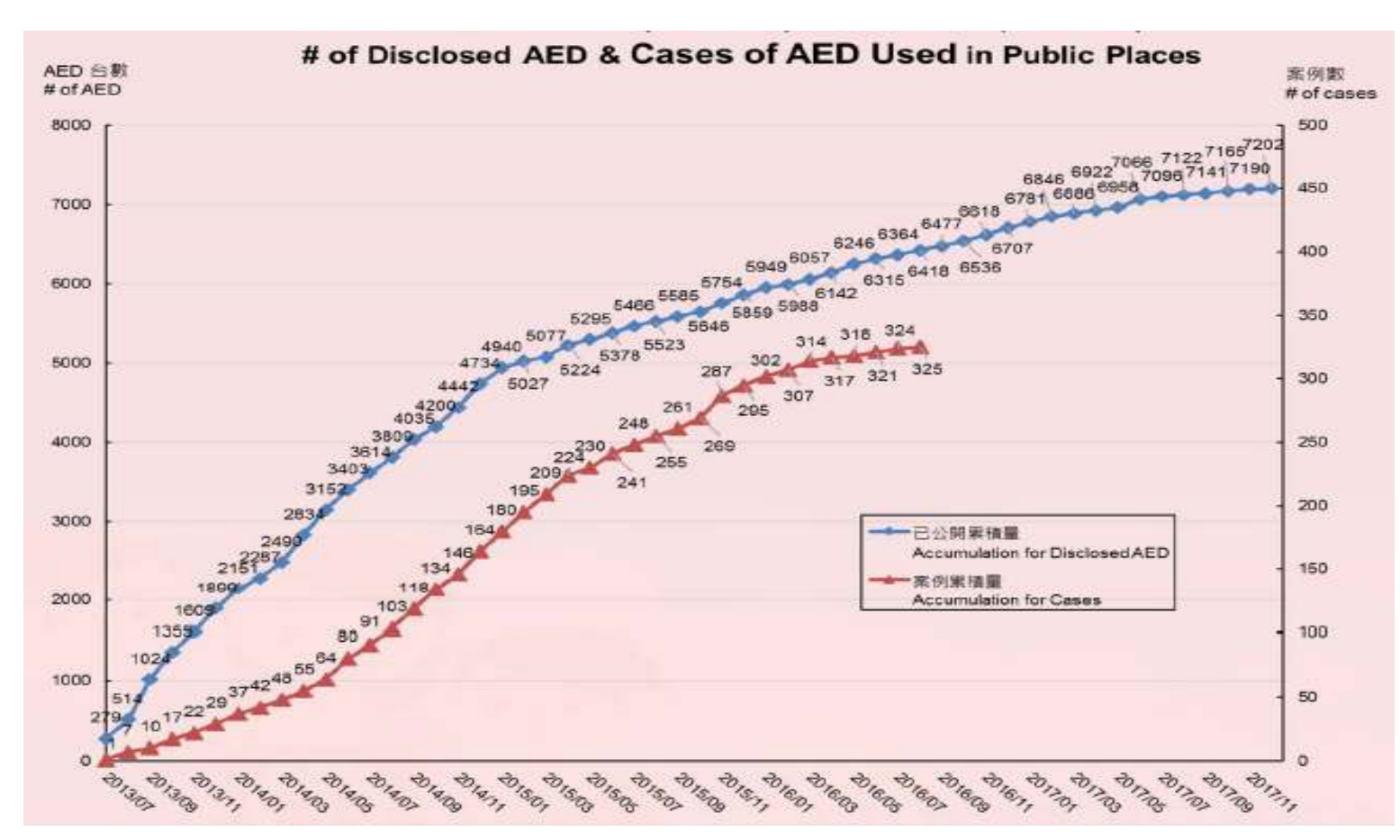

The OHCA The number of registered AED in our country were from 279 $(2013 / 7)$ rised to $7202(2017 / 11)$. The accumulated used seem grow with AED number.

\section{MATERIAL AND METHODS}

The general information of OHCA patients was acquired from Taichung Fire Department. The AED geographic data was collect from national registered system in m Ministry of Health and Welfare. We matched the location between AED and OHCA patients to know the usage and effect of AED.

\section{RESULT}

The OHCA patients attempted to resuscitation by emergency medical technician was 2609 in Taichung city since 2017/1/1-2017/12/31. 395 cases (15.1\%) were collapsed in the public area and 260 cases (10\%) were shock by emergency medical technician. 52 cases (1.9\%) had good neurologic outcome.

There were 952-registered AED at the same time in Taichung city. The usage of AED is only once in 2017. However, there were 1108 patients (43\%) with AED within a distance of less than 300 meters.

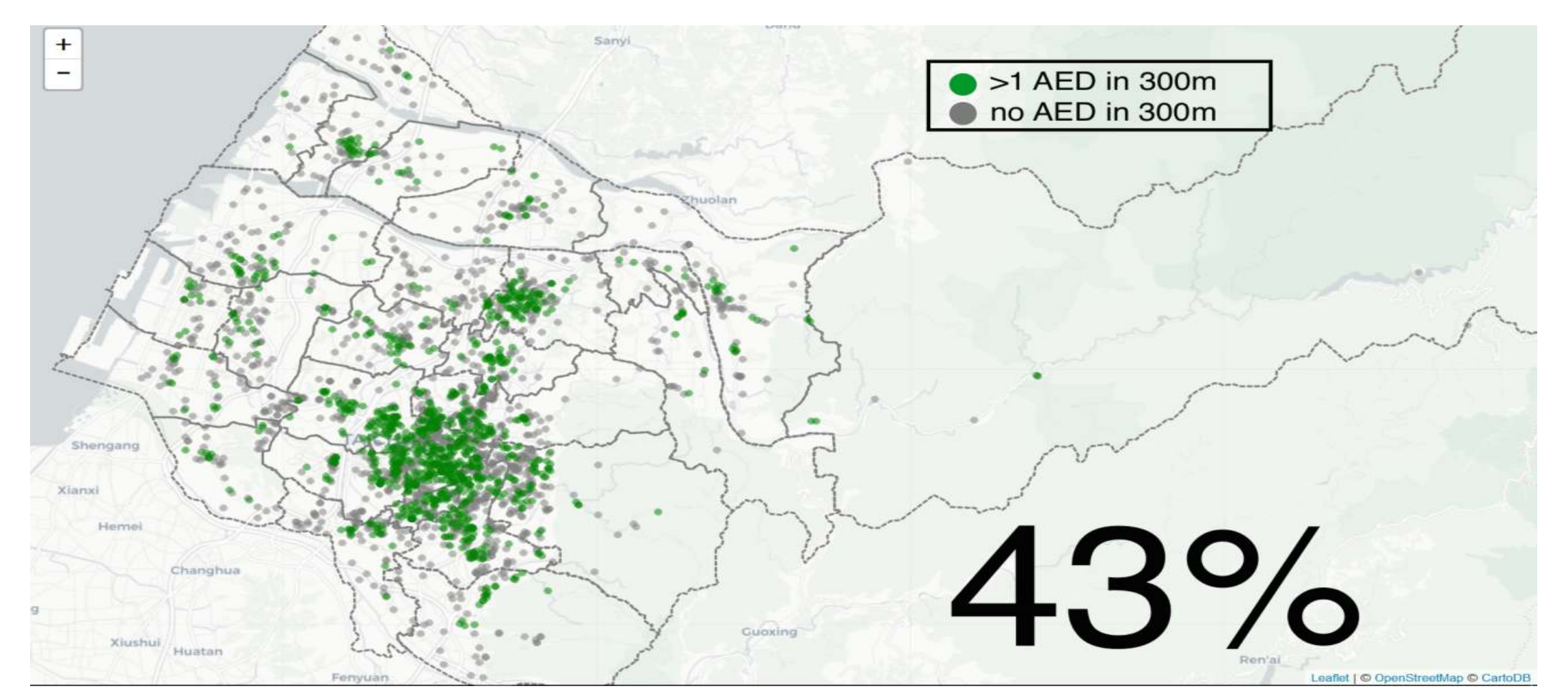

\section{CONCULSION}

Simply setting AED does not seem to increase usage. Maybe need volunteer, education or other device to improving the usage of AED.

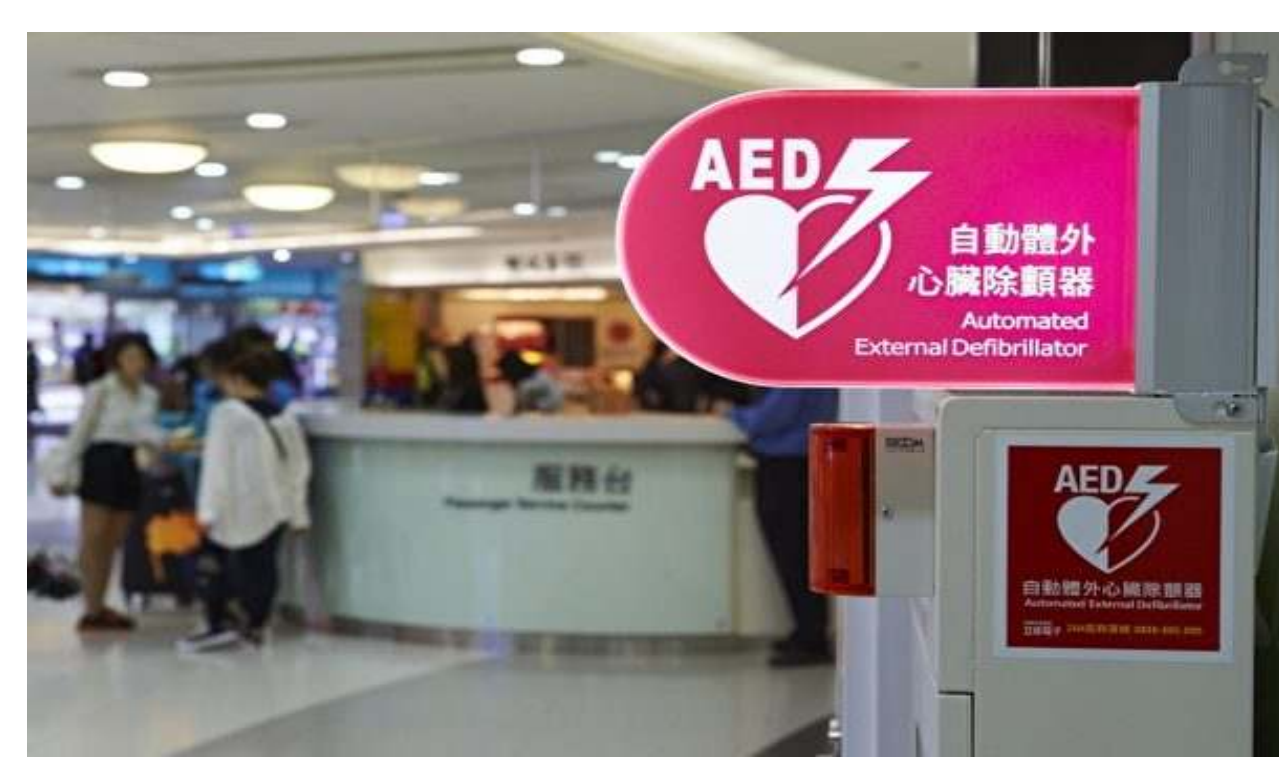

ACKNOWLEDGEMENT

Fire Bureau of Taichung City Gorvernment

Matthew Huei-Ming Ma, M.D., Ph.D 